\title{
A PRODUÇÃO TEXTUAL A PARTIR DE PROCEDIMENTOS DIDÁTICOS: A CONCEPÇÃO DE ESCRITA COMO ASPECTO NORTEADOR DO TRABALHO DOCENTE
}

Ana Cecilia Teixeira Gonçalves ${ }^{1}$

\section{RESUMO}

O presente trabalho tem o objetivo de refletir sobre a aplicação de instrumentos didáticos para o ensino de Língua Portuguesa, sobretudo, voltados para a escrita. Para tanto, fizemos uso da perspectiva do Interacionismo Sociodiscursivo (ISD), pautada nos escritos de Bronckart $(1999,2006)$. Os pressupostos de Vygotsky (1988) também foram de extrema importância para nossa pesquisa. Quanto ao instrumento metodológico analisado, utilizamos uma Sequência Didática (DOLZ, NOVERRAZ e SCHNEUWLY, 2004), cuja finalidade é a internalização de gêneros de texto diversos. A partir dos resultados da aplicação, ficou marcada a relação existente entre a concepção de escrita das instituições e a forma como esse objeto é desenvolvido.

Palavras-chave: Concepção de escrita. Produção textual. Sequência didática.

\section{INTRODUÇÃO}

O estudo realizado teve o propósito de aproximar as pesquisas linguísticas do contexto escolar, focalizando o trabalho com língua escrita na fase de desenvolvimento textual. $O$ objeto de investigação foi, nesse sentido, um instrumento metodológico, o procedimento Sequência Didática (DOLZ; NOVERRAZ; SCHNEUWLY, 2004), que prioriza o trabalho com língua oral e escrita, objetivando o desenvolvimento textual a partir da internalização de gêneros de textos. Esse instrumento possibilitou identificar diferentes formas de se trabalhar com a escrita nos contextos escolares analisados. Assim, em nosso trabalho, a sequência didática representou um instrumento central para acionar a escrita das crianças. Como é 
possível observar, a escrita tem, na instituição escolar, o lugar social privilegiado para sua aquisição e seu desenvolvimento, o que explica nosso interesse nesse contexto.

Por levar em consideração o caráter sócio-histórico da linguagem, e, precisamente, por entendê-la como uma forma de ação social, procuramos embasamento na teoria do Interacionismo Sociodiscursivo - doravante ISD - e nos estudos vygotskyanos sobre linguagem e desenvolvimento humano.

Dos estudos de Vygotsky, base para a teoria do ISD, buscamos destacar a ideia de interação entre organismo humano e meio social, e o consequente desenvolvimento da espécie, assim como o papel central assegurado à linguagem nessa relação. Já no que se refere ao ISD, destacamos o papel fundamental que tem a linguagem nas relações sociais e observamos a aplicação de um objeto de ensino de cunho interacionista que funciona como uma ferramenta para o desenvolvimento de habilidades comunicativas.

Nosso trabalho volta-se, então, para as produções escritas dos alunos com os quais foi desenvolvido o trabalho com Sequência Didática, focalizando alguns pontos em especial:

- o desenvolvimento textual das crianças, a partir da aplicação do instrumento didático, através da comparação de suas produções iniciais e finais;

- os diferentes resultados obtidos, uma vez que o instrumento foi aplicado por professores diferentes em contextos distintos.

\section{A LINGUAGEM COMO UMA FORMA DE AÇÃO SOCIAL}

Para compreendermos o caráter social da linguagem, buscamos embasamento na teoria do Interacionismo Social, cujos princípios gerais foram formulados por Vygotsky. É importante ressaltar, ainda, que é na continuidade desses princípios que Bronckart desenvolve a abordagem do Interacionismo Sociodiscursivo.

Bronckart parte da teoria do Interacionismo Social e desenvolve uma abordagem que prioriza alguns pontos, considerados por ele essenciais e que, devido à morte precoce de Vygotsky, não chegaram a ser trabalhados na íntegra. Conforme Bronckart (1999, p. 21), 
a expressão interacionismo social designa uma posição epistemológica geral, na qual podem ser reconhecidas diversas correntes da filosofia e das ciências humanas [...] essas correntes têm em comum o fato de aderir à tese de que as propriedades específicas das condutas humanas são o resultado de um processo histórico de socialização, possibilitado especialmente pela emergência e pelo desenvolvimento dos instrumentos semióticos.

A teoria propõe que os processos psicológicos tipicamente humanos (ou, como denominou Vygotsky, as funções psicológicas superiores) como, por exemplo, o controle consciente do comportamento, a atenção, a lembrança voluntária, o pensamento abstrato, o raciocínio e outras capacidades têm origem sociocultural e emergem de processos psicológicos elementares de origem biológica. Esse processo de desenvolvimento está arraigado nas relações entre história individual e social. Nesse sentido, o que possibilita o desenvolvimento dessas funções psicológicas superiores é o aparecimento e o desenvolvimento de instrumentos mediadores dessa relação entre indivíduo e contexto social. Assim, a linguagem é a forma principal dessa mediação e, por isso, fundamental para a evolução dos seres humanos.

Para Vygotsky (1988), os processos de transformação do desenvolvimento dos seres humanos têm origens sociais. Nesse sentido, propõe que organismo biológico e meio social não podem ser analisados separadamente; ao contrário, são indissociáveis. Por isso, concede à linguagem um papel fundamental no desenvolvimento do homem, pois, para o autor, é ela a base de outras habilidades mentais do ser humano. Defende que o desenvolvimento dos mecanismos psicológicos mais sofisticados está extremamente relacionado com o contexto social, e, desse modo, ocorre de fora para dentro, no chamado processo de internalização.

Vygotsky (1988) chama de internalização a reconstrução interna de uma operação externa. Esse processo consiste em uma série de transformações:

- Uma operação que inicialmente representa uma atividade externa é reconstruída e começa a ocorrer internamente;

- Um processo interpessoal é transformado em um processo intrapessoal. Vygotsky afirma que todas as funções no desenvolvimento da criança aparecem duas vezes: em um primeiro momento, no nível social, e, depois, no nível individual; primeiro, entre pessoas (interpsicológica), e, a seguir, no 
interior da criança (intrapsicológica). Segundo o autor, todas as funções superiores originam-se das relações reais entre indivíduos.

- A transformação de um processo interpessoal em um processo intrapessoal é o resultado de uma longa série de eventos ocorridos ao longo do desenvolvimento. $\mathrm{O}$ autor ressalta que o processo transformado continua a existir e a mudar como uma forma externa de atividade por um longo período de tempo, antes de internalizar-se por definitivo.

Segundo Vygotsky (1988), a linguagem tem grande importância nesse processo, uma vez que participa fundamentalmente da reconstrução da atividade psicológica. A “internalização das atividades socialmente enraizadas e historicamente desenvolvidas constitui o aspecto característico da psicologia humana" (p. 65).

O processo de internalização é de extrema relevância para nosso trabalho, pois permite compreender como se dá o desenvolvimento da linguagem dentro do ser humano e o seu consequente desenvolvimento, a partir dessa interiorização. Desse modo, ajuda-nos a entender o quanto é importante possibilitar, entre as crianças, o contato com diferentes contextos de utilização da escrita, uma vez que a caracterização do ato de escrever resultaria na sua interiorização.

Vygotsky afirma que a aquisição da linguagem escrita contribui consideravelmente para o desenvolvimento do ser humano. Assim como a fala, a escrita representa um novo instrumento para o pensamento, visto que possibilita o aumento das capacidades do indivíduo (como a memória, por exemplo), além de permitir ao homem pesquisar e conhecer a cultura de sua espécie que está registrada através desse sistema. Nesse sentido, Vygotsky (1988) alega que a escrita desempenha um papel fundamental no desenvolvimento cultural do ser humano.

Para ele, a linguagem escrita é "um sistema particular de símbolos e signos, cuja denominação prenuncia um ponto crítico em todo o desenvolvimento cultural da criança" (VYGOTSKY, 1988, p. 140). Este papel, no entanto, é visto com indiferença, na prática escolar, na qual, de um modo geral, a ênfase é dada a formas mecânicas de aprendizado, desconsiderando-se a essencialidade desse sistema que é a escrita.

Assim, a abordagem do Interacionismo Social apoia-se (sobretudo) no conjunto de princípios defendidos por Vygotsky que, conforme Bronckart (1999, p. 
24), "constitui o fundamento mais radical do interacionismo em psicologia". E, por isso, é também a principal sustentação para a abordagem do ISD.

A abordagem interacionista defende, então, que é ilusório tentar compreender o homem considerando-o apenas sob o aspecto de propriedades biológicas ou comportamentais; ou seja, assumir uma posição em detrimento da outra e ignorar o papel que tem, de fato, o contexto social em seu desenvolvimento. Ao contrário, numa perspectiva interacionista é inevitável que seja assumida a interação entre o organismo humano e o meio social. Nesse sentido, interessada na forma através da qual a linguagem se relaciona com o mundo exterior, a abordagem interacionista tem colaborado para a valorização dessa relação (BRONCKART, 1999).

Para Bronckart (1999), o Interacionismo Social busca investigar o curso da evolução da espécie humana, considerando, de fato, sua "historicidade" Para isso, analisa, em primeiro lugar, o desenvolvimento das organizações sociais, como e por que, no decorrer da evolução da espécie humana, os indivíduos se organizaram socialmente e como, ao mesmo tempo, deu-se o aparecimento e o desenvolvimento de formas de interação. Para o autor, o interacionismo social preserva o "caráter dialético do desenvolvimento da atividade e do psiquismo humano", integrando a ele o papel fundamental que os "instrumentos, a linguagem e o trabalho (ou cooperação social) desempenham na construção da consciência” (p. 22).

Nesse sentido, conforme as considerações de Bronckart (2006), é pela compreensão das manifestações linguísticas como atividades associadas às condutas humanas, socialmente contextualizadas, que se pretende buscar base em teorias que integrem as dimensões psicológicas e sociais ou, como denomina o autor, psicossociais.

\section{OS GÊNEROS E O USO DA LINGUAGEM}

Conforme Bakhtin (1992), as atividades humanas, ricas por suas variadas dimensões, estão relacionadas com o uso concreto de uma língua. Nessa relação entre atividade e linguagem, esta absorve o caráter heterogêneo daquela. Assim, a utilização da língua integra as várias formas de atividades em seus contextos de uso; em decorrência disso, formas linguísticas emergem na comunicação, relacionadas a contextos comunicativos e ativos, nos quais ação e linguagem se misturam e se condicionam. Tal é a dinâmica dos gêneros discursivos. 
Nesse sentido, entendemos que a utilização da língua se dá através de enunciados "orais e escritos", "concretos e únicos", que, conforme Bakhtin (1992), estariam relacionados não só ao contexto de comunicação, como também aos objetivos do locutor. Desse modo, o enunciado apresenta algumas características que são próprias da esfera na qual a língua está sendo utilizada: "Qualquer enunciado considerado isoladamente é, claro, individual, mas cada esfera de utilização da língua elabora seus tipos relativamente estáveis de enunciados, sendo isso que denominamos gêneros do discurso" (p. 279).

Segundo Machado (1998), no contexto escolar, cabe ao professor a escolha de um gênero como ferramenta mediadora das práticas desenvolvidas; essa opção envolve ainda o conteúdo, a forma e, principalmente, papéis atribuídos aos interlocutores nas relações que se estabelecem. Essas considerações apontam para a importante função do professor, uma vez que sua escolha por um determinado gênero traz consigo um grau de responsabilidade, e, nesse sentido, reitera uma concepção defendida por Schneuwly ${ }^{2}$ que vê o gênero como um instrumento.

Para comprovar tal tese, Schneuwly (2004) recorre ao marxismo (Marx e Engels), sublinhando considerações dessa corrente que enfatizam a importância da mediação - do instrumento - na relação entre o sujeito e o objeto. $O$ instrumento, ao possibilitar essa relação, apresenta um caráter social, já que é transmitido nas relações interpessoais e é um fator de desenvolvimento das capacidades individuais.

O autor faz algumas considerações para demonstrar de que forma o instrumento permite o desenvolvimento da espécie humana. Entendendo a atividade dos seres humanos como um acontecimento tripolar, defende que "a ação é mediada por objetos específicos, socialmente elaborados, frutos das experiências das gerações precedentes, através dos quais se transmitem e se alargam as experiências possíveis" (SCHNEUWLY, 2004, p. 23). Assim, o instrumento encontrase em uma posição intermediária, ou seja, entre o indivíduo participante de uma ação e o objeto sobre o qual ele age, ou ainda, um contexto no qual realiza a ação. Esses instrumentos orientam seu comportamento e causam uma percepção diferenciada sobre o contexto de ação. A própria atividade, por sua vez, adquire, com a participação do instrumento, um dinamismo, pois o uso de um determinado instrumento em uma situação específica, ou mesmo, o desenvolvimento de outros instrumentos, orientam nosso comportamento. Nesse sentido, o instrumento não só será o mediador da atividade, imprimindo-lhe certa forma, como também 
representará essa atividade, fazendo com que ela exista nos instrumentos que irão significá-la. Constrói-se, assim, uma relação muito próxima entre o uso do instrumento e sua atividade, tanto que a transformação daquele gera, consequentemente, mudanças na atividade relacionada ao seu uso.

Outra consideração analisada por Schneuwly (2004, p. 24) diz respeito ao instrumento mediador. $\mathrm{O}$ autor afirma que $\mathrm{o}$ instrumento apresenta duas faces:

\begin{abstract}
por um lado, há o artefato material ou simbólico, isto é, o produto material existente fora do sujeito, materializando, por sua própria forma, as operações que tornam possíveis os fins aos quais o instrumento é destinado; por outro lado, há os esquemas de utilização do objeto que articulam suas possibilidades às situações de ação.
\end{abstract}

Conforme 0 autor, 0 instrumento só apresenta esse caráter de objeto mediador na medida em que é apropriado pelo sujeito, isto é, quando o indivíduo constrói internamente os esquemas de utilização desse instrumento, e, em consequência, adquire conhecimentos sobre o mundo. Dessa forma, esse objeto mediador determina ações que são possíveis de serem realizadas através das finalidades que podem ser atingidas graças a ele. Podemos notar que durante o desenvolvimento da ação, o instrumento não só a orienta, como também a controla.

Schneuwly (2004, p. 26) recorre às definições de Bakhtin sobre os gêneros para fazer a analogia com o instrumento e chega a três pontos principais:

- Em primeiro lugar, a escolha de um gênero requer conhecimento sobre o contexto de ação e de suas convenções.

- Esse conhecimento da situação e de seus parâmetros leva à escolha de um gênero dentre vários;

- Os gêneros são relativamente estáveis e, dessa maneira, definem o que pode ser dito; também, possuem uma composição, assim, "eles têm uma estrutura definida por sua função"; por fim, são caracterizados por um estilo, elemento de um gênero.

Essas características destacadas por Schneuwly apontam para uma aproximação entre o gênero e o instrumento. Vejamos melhor: em uma ação discursiva - ato de fala ou escrita - há um sujeito, inserido em um contexto definido por um conjunto de convenções, que utiliza um gênero, "instrumento semiótico complexo"; uma forma de linguagem que apresenta um caráter prescritivo e estabilizador, e que possibilita a produção e compreensão de textos. Como 
sabemos, a escolha por um gênero é feita em decorrência de uma situação. Para Schneuwly (2004), ocorre aqui uma relação entre meio-fim, como nas atividades mediadas por um instrumento.

\section{APLICAÇÃO PEDAGÓGICA DO INTERACIONISMO SOCIODISCURSIVO}

Na teoria do ISD, os estudos voltados para o ensino-aprendizagem de língua materna defendem a ideia de que, ao invés de priorizar um ensino baseado em regras prescritivas, deve-se trabalhar com atividades que possibilitem 0 desenvolvimento da competência comunicativa dos alunos. Desse modo, a utilização dos gêneros na escola é defendida por autores dessa linha de pesquisa, como Dolz e Schneuwly. O trabalho com gêneros deve priorizar justamente aspectos comunicativos, como o aumento da capacidade de se comunicar dos aprendizes, e não mais considerar apenas aspectos estruturais e formais - o que geralmente acontece quando o gênero é utilizado como recurso didático ${ }^{3}$.

Nesse sentido, defende-se que o estudo de gêneros no âmbito escolar pode ser de grande importância para o desenvolvimento das capacidades de se comunicar dos alunos, uma vez que leva em consideração o uso da linguagem, assim como suas funções, em uma situação comunicativa de fato. A utilização dos gêneros como objeto de estudo colabora para uma mudança no contexto tradicional no qual estão pautadas as aulas de Língua Portuguesa. Com o estudo dos gêneros, tem-se um contexto de ensino-aprendizagem rico em interação, nas mais diversas situações comunicativas que podem ser geradas.

Antes de serem utilizados como objetos de estudo na escola, entretanto, os gêneros devem passar por uma modelização didática, isto é, uma série de transformações sofridas por um gênero até este se transformar em um gênero escolar. Veremos, a seguir, como se dá esse desdobramento. (DOLZ e SCHNEUWLY, 2004)

\subsection{A didatização do gênero}

De acordo com Bronckart, "a noção de texto designa toda unidade de produção de linguagem que veicula uma mensagem linguisticamente organizada e que tende a produzir um efeito de coerência sobre o destinatário" (1999, p. 71). Essa 
concepção de texto como "unidade comunicativa" se diferencia da prática educacional tradicional, na qual o trabalho com textos, na maioria das vezes, tem como objetivo a avaliação dos alunos.

Ao entender o trabalho com textos na escola de forma diferenciada, podemos pensar nas possibilidades de trabalho que este instrumento nos oferece. Nessa perspectiva, fica evidente a importância que há em fazer de textos objetos de trabalho para o ensino. Conforme Schneuwly e Dolz (2004), a escolha de textos para o ensino possibilita trabalhar fenômenos de textualidade em relação com as situações de comunicação, o que torna o ensino bem mais significativo.

Como vimos, podemos diferenciar vários tipos de textos conforme seus contextos de produção. As situações de comunicação são inúmeras, dessa forma, para que a interação linguística seja possível, a sociedade elabora formas relativamente estáveis de textos as quais denominamos de gêneros. Notamos que, nesse sentido, os gêneros podem ser considerados instrumentos que possibilitam a comunicação e, também, a aprendizagem (SCHNEUWLY; DOLZ, 2004).

Conforme Schneuwly e Dolz, o ensino de gêneros constitui um ponto de referência concreto para os alunos, uma vez que os dota de "meios de análise das condições sociais efetivas de produção e de recepção de textos" (2004, p. 172). Ao utilizar os gêneros como objetos de ensino, a escola cumpre seu papel, que é, sob o ponto de vista do ISD, o de instruir, fazendo com que os alunos ultrapassem as formas cotidianas de uso da linguagem.

Uma modelização didática do gênero sugere, primeiramente, que se conheçam as características do gênero em questão: "a noção de gênero permite articular a finalidade geral de aprender a comunicar com os meios linguísticos próprios às situações que tornam a comunicação possível" (SCHNEUWLY; DOLZ, 2004, p. 177). Com isso, determina-se o que pode ser interessante ensinar.

A caracterização é importante para definir o objeto de ensino e o que pode ser ensinado de tal objeto, no entanto, esses dados não podem ser diretamente transpostos para a sala de aula, uma vez que "a entrada de um gênero na escola transforma-o necessariamente [...] é necessário que se levem em conta as capacidades de linguagem que visamos construir com os alunos, em um dado momento de seu progresso" (SCHNEUWLY; DOLZ, 2004, p. 179).

Portanto, é preciso transformar o objeto de ensino (o gênero) para ensiná-lo aos alunos, chegando, assim, à variante escolar do gênero. Segundo Schneuwly e 
Dolz (2004), quando um gênero textual passa a ser ensinado na escola, produz-se um desdobramento, isto é, este gênero torna-se, ao mesmo tempo, "um instrumento de comunicação e um objeto de aprendizagem" (p. 179). Nesse sentido, a utilização dos gêneros como objetos de ensino exige transformações, assim, os gêneros escolares podem ser definidos como variantes dos gêneros de referência. A transposição para a escola de um gênero tem como intuito tornar esse objeto mais acessível aos aprendizes, também, como consequência, ela muda a função desse gênero, que passa a fazer parte de outra situação comunicativa": "somente ficcionalmente ele continua o mesmo, por assim dizer, sendo a escola, de um certo ponto de vista, um lugar onde se finge, o que é, aliás, uma eficiente maneira de aprender" (2004, p. 180).

Pensando nessas transformações que são necessárias quando um gênero torna-se objeto a ser ensinado na escola, Schneuwly e Dolz desenvolveram um modelo didático que evidencia suas dimensões ensináveis. Segundo Schneuwly e Dolz (2004, p. 180), o desenvolvimento de um modelo didático pressupõe a explicitação de um conjunto de hipóteses fundadas sobre determinados dados disponíveis:

- determinados resultados de aprendizagem esperados e expressos em documentos oficiais;

- conhecimentos existentes, linguísticos (funcionamento dos gêneros) e psicológicos (operações e procedimentos implicados no funcionamento e na apropriação dos gêneros);

- determinação das capacidades mostradas dos aprendizes (que não permitem definir uma zona de desenvolvimento proximal, porém, permitem que esbocemos alguns contornos).

Assim, a relação entre esse conjunto de dados possibilita constituir o que De Pietro et al (1996/1997 apud SCHNEUWLY; DOLZ, 2004), definem como modelo didático do gênero. Deste modelo, definimos os princípios (o que é o gênero em questão), os mecanismos e as formulações que passarão a ser ensinadas, isto é, que devem constituir os objetivos de aprendizagem dos alunos.

Dessa maneira, o modelo didático fornece "objetos potenciais para o ensino" (SCHNEUWLY; DOLZ, 2004, p. 182). Potenciais porque uma seleção deve ser realizada a partir das capacidades dos aprendizes, e, ainda, porque o modelo não 
poderia ser ensinado tal como é; o gênero modelizado será expresso a partir de atividades, de transformações, de informações.

A noção de modelo didático possibilita um trabalho com ensino de língua na escola que se distancia do que se tem de referente nas aulas de Língua Portuguesa: uma prática tradicional que prioriza o ensino de nomenclaturas e utiliza o trabalho com textos como forma de avaliar o aluno. Como proposta de mudança desse contexto, contamos com a noção de modelos didáticos e, a partir deles, com as chamadas Sequências Didáticas, ferramentas de cunho interacionista extremamente importante para o ensino de língua materna, tal como é proposto, através dos modelos didáticos, pelo ISD.

\subsubsection{Sequências didáticas: perspectivas teórico-metodológicas}

Entendemos que 0 ensino de língua materna deve possibilitar 0 desenvolvimento de atividades diferenciadas do que se tem de referente - que possa centralizar o trabalho com textos, com a expressão linguística -, agregando a isso o ensino da gramática.

Segundo Dolz, Noverraz e Schneuwly (2004), é possível "ensinar a escrever textos e a exprimir-se oralmente em situações públicas escolares e extra-escolares" (p. 96). Para isso, é preciso oferecer, aos alunos, variados contextos de produção, tanto de fala quanto de escrita, para que possam desenvolver suas capacidades de expressão.

Como proposta de trabalho, Dolz, Noverraz e Schneuwly (2004) desenvolveram um procedimento chamado de Sequência Didática: "uma sequência didática é um conjunto de atividades escolares organizadas, de maneira sistemática, em torno de um gênero textual oral ou escrito" (p. 97). Esse procedimento apresenta como principal característica o fato de trabalhar com gêneros, auxiliando o aluno a dominar alguns de forma completa; "as sequências didáticas servem, portanto, para dar acesso aos alunos a práticas de linguagem novas ou dificilmente domináveis" ( $p$. 98). Além disso, possui uma estrutura de base diferenciada:

- tem-se, primeiramente, a apresentação da situação em que são dadas informações sobre a atividade (oral ou escrita) que deverá ser desenvolvida;

- em um segundo momento, ocorre a primeira produção dos alunos correspondente ao gênero proposto para o trabalho; a partir dela, é possível 
que o professor avalie as capacidades já adquiridas, o que propicia o ajustamento das atividades e dos exercícios previstos na sequência às possibilidades e deficiências da turma;

- em seguida, ocorre o desenvolvimento dos módulos: são eles que dão os "instrumentos necessários" para o domínio do gênero, através de atividades, oficinas, etc. É o professor que decide o número de módulos que a sequência vai ter, uma vez que eles devem suprir as dificuldades apresentadas pela turma;

- por fim, tem-se a produção final, nessa etapa, o aluno "põe em prática" os conhecimentos adquiridos; o professor, por sua vez, tem possibilidades de ver quais foram os progressos apresentados nas produções.

Dolz, Noverraz e Schneuwly (2004, p. 127) salientam alguns aspectos de ordem metodológica para que esse trabalho não se torne estático. Para isso, enfatizam o fato de que o tempo utilizado para o desenvolvimento do mecanismo, bem como o percurso feito pelo professor, não precisam ser estritamente seguidos. É importante evidenciar que o professor irá receber a sequência pronta, mas seu trabalho não estará acabado; a partir daquela orientação realizará uma atividade de acordo com as dificuldades da turma. Nesse sentido, conforme os autores, delimitar esses pontos seria entrar em contradição com o princípio fundamental da proposta: "que é de partir do que já está adquirido pelos alunos para visar a objetivos de aprendizagem relacionados com suas capacidades reais". Dessa forma, "as sequências não devem ser consideradas como um manual a ser seguido passo a passo. Para o professor, a responsabilidade é efetuar escolhas, em diferentes níveis".

Portanto, o professor escolhe a sequência que está de acordo com uma determinada série/ano, como também os módulos a serem realizados; a "proposta só assume seu sentido completo se as atividades desenvolvidas em sala de aula, e não o material à disposição, forem determinadas pelas dificuldades encontradas pelos alunos na realização da tarefa proposta" (DOLZ; NOVERRAZ; SCHNEUWLY, 2004, p. 127). Por isso, é tão importante que o professor faça uma análise das primeiras produções realizadas pelos alunos. Através delas, poderá escolher as atividades a serem realizadas e para quem devem ser direcionadas.

Dessa forma, entendemos que o objetivo de produzir sequências didáticas para que o professor trabalhe em sala de aula não deve ser confundido com um 
modelo obrigatório a ser seguido; o professor deve utilizar esse procedimento como uma orientação metodológica para um trabalho com ensino de língua materna. Cabe, então, tomá-las, não como um modelo sistemático que deve ser seguido independentemente das dificuldades que sua aplicação pode acarretar aos alunos, mas, ao contrário, como uma orientação que possibilite o desenvolvimento de um trabalho, no qual o professor tenha autonomia e liberdade de escolha. É isso que procuramos observar em nossa pesquisa, uma vez que analisamos o processo de construção da escrita a partir do recorte metodológico possibilitado pela aplicação de uma mesma sequência didática, por professores diferentes. Focalizamos, nesse sentido, o desenvolvimento textual dos alunos, através da comparação entre o texto inicial e o texto final.

\section{APLICAÇÃO DA SEQUÊNCIA DIDÁTICA NARRATIVA DE CONTOS DE DETETIVE}

A aplicação ${ }^{5}$ do procedimento didático foi realizada em uma escola pública de Ensino Fundamental, pertencente ao sistema Municipal de Ensino de Santa Maria (RS) - identificada por Escola A; e em uma escola dirigida por uma instituição privada que tem, como público, crianças carentes - identificada como Escola B. As duas escolas estão localizadas em zonas periféricas da cidade; seus alunos pertencem a camadas populares e, na sua maioria, apresentam grandes dificuldades socioeconômicas.

Neste estudo ${ }^{6}$, será considerada a atividade realizada com duas turmas: uma delas pertencente ao $5^{\circ}$ (quinto) ano, na escola municipal; e outra pertencente à $5^{\underline{a}}$ série, na escola privada. Na escola $A$, o professor regente tinha como formação o Magistério; na escola B, o professor era formado em Letras e cursava o Mestrado na área dos Estudos Linguísticos.

Apresentamos como proposta de trabalho, a esses profissionais, a aplicação do procedimento Sequência Didática "Narrativa de Contos de Detetive", uma adaptação da Sequência Didática de autoria da Profä. Dr. Ana Maria de Mattos Guimarães (2004), do PPLA da UNISINOS.

Evidenciamos a importância que havia em observarmos suas práticas pedagógicas em situações concretas, isto é, na sala de aula. Os dois se 
disponibilizaram a participar do projeto. Enquanto a turma da Escola A tinha em média vinte e cinco alunos, a da Escola B possuía quarenta estudantes.

O objeto de nossa investigação é, dessa forma, o procedimento Sequência Didática e a escrita da criança resultante da atividade, analisada sob o recorte teórico-metodológico do ISD. Assim, depois de aplicada a Sequência Didática, obtivemos um grande número de textos, dentre os quais escolhemos um número de produções de cada grupo ${ }^{7}$.

\section{DISCUSSÃO DOS RESULTADOS}

Passamos, neste momento, para a análise dos textos dos sujeitos da pesquisa. Por uma questão estrutural, analisaremos apenas dois textos de cada grupo: a produção inicial e a produção final de um sujeito de cada escola.

Com o objetivo de realizar uma avaliação eficaz dos textos produzidos a partir da sequência didática aplicada, analisamos ${ }^{8}$ as produções iniciais e finais tomando por base o modelo proposto por Bronckart (1999), focalizando o conteúdo temático, os tipos de discurso, a organização sequencial do texto e o posicionamento enunciativo.

O conteúdo temático - pertencente à primeira camada do folhado textual está relacionado, conforme Bronckart (1999), ao gênero a que pertence o texto e às condições externas de produção. De acordo com Guimarães (2004), o conteúdo temático pode ser analisado quanto ao léxico típico, quanto às situações típicas relacionadas ao gênero em questão e quanto às personagens típicas.

Os tipos de discurso - pertencentes, também, à primeira camada do folhado - correspondem às unidades linguísticas que podem estar presentes na constituição de qualquer gênero. Dessa forma, um mesmo gênero, segundo Bronckart (1999), pode ser constituído de diferentes tipos de discurso. Por ter trabalhado com narrativa, os textos analisados apresentam dois tipos de discurso: o relato interativo e a narração.

No que diz respeito à organização sequencial, o procedimento didático em questão trata do gênero Narrativa de detetives. Segundo Bronckart (1999), esse tipo de gênero pertence à ordem do narrar, dessa forma, seus textos são caracterizados por apresentarem uma relação de autonomia em relação ao autor, ao lugar e ao momento de produção. Nesse sentido, apresenta uma sequência narrativa que, 
conforme Adam (1992), pode ser organizada em cinco diferentes fases: situação inicial (apresentação dos elementos da trama, como as personagens, o momento, o lugar, as dificuldades), fase da complicação (introdução de um elemento que modifica a situação inicial), fase de ações (envolve um conjunto de acontecimentos), fase de resolução (acontecimentos que possibilitam a resolução do problema) e situação final (novo estado de equilíbrio).

Já o posicionamento enunciativo, segundo Bronckart (1999), diz respeito às instâncias formais (textualizador, expositor, narrador) em que são distribuídas as vozes (voz do autor empírico, voz social e voz de personagens) expressas em um texto. Na narrativa de detetive, a instância enunciativa será o narrador; cabe a ele dar voz às personagens ou fazer avaliações sociais, etc.

Os textos analisados são resultados da primeira e da última produção desenvolvidas na sequência didática. No que diz respeito ao primeiro texto, foi dado um tema para que as crianças fizessem a produção. $O$ tema era o seguinte: 0 sumiço do meu colega. Já quanto ao último texto, não houve esse tipo de procedimento; foi pedido às crianças apenas que, com base no que haviam estudado durante as aulas, produzissem uma história de detetive.

Vejamos os textos:

\section{Grupo 1 - Escola A: Sujeito X - 11 anos}

\section{Produção inicial}

\section{O sumiço do meu colega}

A minha colega Michele sumil da Escola Porque sera que ela sumil você sabe por que ela sumil.

Eu queria que você me achudace a trazer ela para a escola de novo por que a escola é mais importante para ela a escola e a vida sem Escola não tem vida. 


\section{Produção final}

\section{As crianças morrem.}

Era uma vez 6 crianças estavam brincando no jardim e chegou outro menino correndo e critando socorro, socorro.

Na rua Inlda berleze e ai os meninos e as meninas morrero no padio mas eles ajavam que foi um binjo que mordeu pás um viu a faca no pindurada no menino e na menina uma arma na cabeça e nos outro tinha marca da Arma.

E o detetive Henrique perguntou os nomes das crianças por favor. Luiz, Gabriel, Lucas, Bruna, e Luiza, Mara.

Ele envestigou moreu mas uma criança do mesmo jeito da soltras o nome dele é dionas mas encontraram o açasino qie mantou as 7 crianças. Era o detetive Henrique ele matou porque era loco.

Fim.

O primeiro texto não apresenta nenhum elemento característico da narrativa de detetive. Notamos, quanto ao posicionamento enunciativo, uma voz social que salienta a importância da escola: "a escola é a vida".

Na produção final, observamos, inicialmente, a ocorrência do léxico típico dos contos de fadas: "era uma vez". Existe a presença de um crime; aparece um detetive na história, que também será o antagonista, uma vez que é ele o assassino.

A narrativa apresenta alguns problemas na constituição de suas fases. Há uma situação inicial e uma complicação, entretanto, não há uma investigação, que caracterizaria a narrativa de detetive. Em consequência, a resolução deixa a desejar, visto que não sabemos a razão pela qual o antagonista, neste caso, o próprio detetive, comete os crimes.

A mudança mais significativa entre o texto inicial e o final diz respeito ao tipo de discurso utilizado: passa-se do relato interativo (na produção inicial) para a narração (produção final). 


\section{Grupo 2 - Escola B: Sujeito Z - 11 anos}

\section{Produção inicial}

\section{O sumiço do meu colega}

Estava com minha colega antes de bater na entrada. Ela me falou que iria tomar água no bebedouro do corredor. Eu falei tudo bem, eu estarei no banco azul te esperando. Bateu e eu não vi ela então eu fui para o campo.

Isto foi numa segunda-feira que a turma de capoeira começava 8 horas eu esperei todos as turmas entrar. Quando e fui sair do campo me dei de cara com a turma de capoeira e o professor pegou e perguntou a mim o que eu estava fazendo lá na quele horario de aula e eu falei para o professor que estava procurando a minha colega.

Mas o professor sabe disto sim claro foi ele que me mandou procurar ele porque ela desapareceu de uma hora para outra. O professor perguntou se eu não queria ficar olhando eu disse que sim holhei um pouco e me animei e joguei capoeira pela primeira vez na frente do professor

Quando eu sai para procurar ela eu me deparei com ela jogando espirobol com outras gurias que tambem falharam aula e eu voltei para a capoeira - por que para a sala eu não emtraria atrasadicima

\section{Produção final}

\section{Porque as mortes}

Uma aluna de Bervely Hills?? Foi assassinada na noite de 2 de maio de 1987, por alguém que nunca foi revelado porque não encontraram pistas. Certa? menina se chamava Mia Conrad Brilhanti

Os anos se passaram e várias pessoas morreram e todas do colegio de Bervely Hills e com o sobrenome Brilhanti. Os investigadores não sabiam mais o que fazem para descobrir quem era o culpado. Eles tinham suspeitas como um exfuncionário da fábrica (apetrechos Brilhantes) e o funcionário se chamava Carlos 
A fábrica foi fundada pela familha Brilhante e este ex-funcionário não gostava da famílha porque um dos Brilhantes demitio este funcionário. Ele ficou com raiva da familha Brilhanti

Em uma destas mortes o assassino também foi ferido e tirou a blusa cheia de sangue e largou um pouco depois da praça velha omde não havia casas perto e onde ele matou Renato Comrad Brilhanti

E foi ate o hospital derramando sangue ao chão. No outro dia, uma pessoa estava passando pela praça velha e viu o corpo do jovem e ligou para a polícia. $A$ policia veio o mais de pressa chegando com a perícia. Logo Davidi foi examinando e seguindo o sangue. Ele viu que tinha sangue até o hospital e ele foi ao hospital

Ver se havia chegado algumas pessoas machucadas. A noite o médico disse que avia chegado dois pacientes um as 9:30 que era o ex-funcionário e o outro as 11:00

Logo a policía pensou que era o funcionario. Mas Deivid falou ao policial para colocar um guarda em cada Quarto para cuidar os homens. Fizeram o perícia e pegaram uma amostra de sangue.

O resultado foi que o homem sem nome foi o culpado pelas mortes, mas porque isto aconteceu? Os médicos falaram que ele chegou falando que ia matar todos da familia Brilhante porque eles haviam roubado a casa da familia dele.

O policial falou: mas claro! Este cara e Miguel Jessus Balaros o pai dele perdeu a casa deles em jogo. Miguel disse na minha frente: "eu juro ainda matareis esta familia por que não perdoaram a divida de jogo que meu pai fez e não tiveram pena di mim de minha familia"

O policial prendeu o homem depois que ele se recuperou do tiro no Braço que levou de Roberto

A produção inicial trata-se de um relato interativo e não apresenta características de uma narrativa de detetive. Podemos observar que o autor enfatiza mais o fato de ter jogado capoeira do que o sumiço do colega, afastando-se, desse modo, do tema central da história. Notamos, também, a ocorrência de vozes de personagens no decorrer do relato interativo que não são marcadas linguisticamente com o travessão: Mas o professor sabe disto sim claro foi ele que me mandou procurar ele. Nesta passagem, por exemplo, é possível observar a voz de duas 
personagens diferentes - o professor de capoeira e a menina que se perdeu da colega - que acabam expressas de forma indireta.

Já quando observamos a produção final, o desenvolvimento do texto é notável e a produção representa uma narrativa de detetive muito bem elaborada. Até mesmo os nomes das personagens são criativos: "Mia Conrad Brilhantr", "Renato Comrad Brilhanti", "Miguel Jessus Balaros". Identificamos a presença de todos os elementos do conteúdo temático: o vocabulário específico da narrativa de detetive mortes, assassinada, investigadores, perícia, etc -, as personagens típicas, a ocorrência de mistério/crime. O texto possui todas as fases da sequência narrativa, salientando-se, em especial, a fase de resolução, em que notamos uma preocupação por parte do sujeito de mostrar a razão pela qual o antagonista comete os crimes: "O resultado foi que o homem sem nome foi o culpado pelas mortes, mas porque isto aconteceu?'. O resultado é um enredo muito criativo, além de se tratar de uma narração, de fato, ao contrário do primeiro texto, no qual o discurso utilizado foi o relato interativo.

\section{CONSIDERAÇÕES FINAIS}

É importante ressaltar que o instrumento de trabalho utilizado tem como característica a focalização na aprendizagem de habilidades textuais através de atividades voltadas para a utilização da língua, em especial para a escrita: o foco passa da gramática para a linguagem oral e escrita. A sequência didática possibilita a aprendizagem de diferentes espécies de textos, ou melhor, a criança toma conhecimento de gêneros de textos diversos. Organiza-se a sequência didática em torno de um gênero; a criança passa por um conjunto de atividades - que podem ser voltadas principalmente para o uso da linguagem escrita - até que internaliza essas informações e o determinado gênero passa a ser mais um tipo de texto sobre o qual teria conhecimento. Trata-se, desse modo, de uma forma de trabalho que preconiza o desenvolvimento de atividades voltadas para a língua, especialmente para a escrita, proporcionando a aprendizagem de habilidades comunicativas.

O trabalho foi desenvolvido em duas instituições diferentes - identificadas como escola A e escola B - porém, com o mesmo perfil de público. É importante ressaltar ainda que, para a maioria desses sujeitos, a escola representa o único lugar em que podem interagir com atividades de leitura e escrita. Embora com um 
público semelhante, estas escolas apresentaram características bastante diferenciadas no que diz respeito à escrita resultante da aplicação do procedimento didático, o que será observado a seguir.

A diversidade dos resultados obtidos ${ }^{9} \operatorname{com}_{\text {a }}$ aplicação da sequência didática nos levou, em um primeiro momento, a focalizar a figura do professor: a formação distinta, assim como a concepção de língua e de escrita. Afinal, um professor tinha apenas o Magistério, em contrapartida o outro era um professor formado em Letras, iniciando uma pós-graduação em Linguística. Assim, os resultados, obrigatoriamente, deveriam ser diferentes. Entretanto, a reflexão sobre os resultados foi aos poucos nos mostrando outro caminho, e o foco de nossa discussão foi deixando de ser o trabalho do professor. Em um determinado momento, ficou evidente que os resultados obtidos com a sequência didática, e com o trabalho com escrita que ela sugere, refletem não apenas a postura de um profissional singular, mas, antes disso, a posição de uma instituição (escola) frente ao trabalho com língua escrita. Essa constatação torna-se clara ao analisarmos as produções dos grupos com os quais realizamos a aplicação da sequência.

Embora pertencentes a contextos sociais semelhantes, as crianças alcançaram resultados diferentes no desenvolvimento da sequência didática. $A$ análise dos textos do grupo 1, pertencentes à Escola $A$, demonstra que esses alunos não estão habituados a atividades de escrita na escola.

O grupo 1, no qual o trabalho foi desenvolvido pela professora da turma profissional que segue uma tradição gramatical no ensino de língua materna - não atingiu o objetivo da sequência didática; nem mesmo demonstraram ter conhecimento sobre a estruturação básica de um texto. Os sujeitos apresentam sérios problemas de ortografia e de organização estrutural; a estética do texto é muito primária. Nesse sentido, além de não conseguirem formular um texto com ideias claras, não possuem conhecimentos linguísticos básicos de estrutura e ortografia.

Se compararmos esses textos (do grupo 1) com as produções do grupo 2, da escola $B$, notamos uma diferença relevante. Mesmo se tratando de um público homogêneo, que têm acesso a atividades de ler e escrever somente na escola, os resultados demonstram diferenças consideráveis. Já no texto inicial, os sujeitos do grupo 2 demonstram ter domínio das marcas da escrita que os sujeitos do grupo 1 
não apresentaram nem mesmo no texto final. Essa afirmação se evidencia quando observamos as produções destes grupos.

São textos bem estruturados, com domínio das regras ortográficas (levandose em consideração a série em que as crianças estão), e mais extensos. As crianças têm noção de parágrafo, de pontuação, e as ideias são expostas com clareza. No último texto, vão aparecer as características do gênero, que não estavam presentes nas produções iniciais, demonstrando que o resultado do trabalho com a sequência didática foi positivo.

A aplicação do objeto de ensino, dessa maneira, alcançou os resultados esperados, uma vez que os sujeitos aprenderam uma nova forma de comunicação, nesse caso, a escrita de uma narrativa de detetive.

Esses diferentes resultados apontam para um fato interessante: na Escola $A$, o trabalho com sequência didática parece ter representado um evento único de escrita, uma novidade e, por essa razão, não deu conta de resolver os problemas surgidos no decorrer da atividade. Na Escola B, em função dos resultados obtidos, concluímos que a sequência didática provavelmente representou apenas mais uma atividade de escrita proporcionada aos alunos. Nesse sentido, na Escola B, podemos inferir que 0 ato de escrever faz parte da rotina das crianças, e, a partir disso, deduzir também que se trata de uma questão política da instituição.

Nesse sentido, temos uma situação paradoxal: em contextos próximos, no qual os sujeitos têm acesso à escrita na escola, a atividade de escrita parece representar, de um lado, um evento único e, de outro, um ato rotineiro.

Esses resultados remetem a uma constatação importante: uma proposta metodológica, por mais que esteja embasada em uma teoria respeitável e por melhor que sejam seus objetivos, não resolve os problemas de escrita dos alunos. Temos como exemplo a sequência didática - um procedimento voltado para o trabalho com escrita, que objetiva o aprendizado, por parte das crianças, de formas novas de comunicação, tendo como base uma teoria sociointeracionista, segundo a qual a participação dos outros é fundamental no processo de aprendizagem (nesse caso, instituição, professor, colegas etc., mediadores no processo), - mesmo este instrumento metodológico não conseguiu resolver os problemas de escrita dos sujeitos. Essa situação sugere que o desenvolvimento da escrita no contexto escolar é uma questão mais ampla: sem uma política de escrita, envolvendo toda a escola, não há possibilidade de mudança do quadro atual de ensino. 


\title{
NOTAS
}

${ }^{1}$ Professora da Universidade Federal da Fronteira Sul, campus Cerro Largo/RS, e doutoranda em Estudos Linguísticos pela Universidade Federal de Santa Maria.

${ }^{2}$ Ao entender o gênero como um instrumento, Schneuwly faz alusão ao sentido que Vygotsky dá ao termo instrumento. Sobre o assunto, ver Vygotsky (1988).

${ }^{3}$ É importante salientar que a inclusão dos gêneros nas escolas brasileiras é ainda pouco expressiva; o próprio conceito de gênero parece não muito claro aos professores.

${ }^{4}$ Cumpre-nos salientar que a produção escrita tem como objetivo principal a interação: o sujeito/escritor escreve para alguém ler.

${ }^{5}$ A aplicação da Sequência didática ocorreu durante o ano de 2006.

${ }^{6}$ É importante esclarecer que a sequência didática foi aplicada em três turmas, duas pertencentes à escola municipal e outra, à escola privada. Os dados obtidos no trabalho foram organizados em três grupos, cada um referente à participante que aplicou a sequência didática: na escola municipal, em uma turma, a professora e, em outra, a pesquisadora; na escola privada, a professora regente. Cada grupo era constituído por seis sujeitos, sendo que foram analisados dois textos de cada participante: o primeiro texto e a produção final, ambos desenvolvidos durante a aplicação do procedimento. Por uma questão organizacional, neste artigo, serão focalizados apenas os grupos nos quais a atividade foi realizada pelos professores das escolas.

${ }^{7}$ Nosso corpus era composto de trinta e seis textos no total.

${ }^{8}$ Para essa análise, baseamo-nos no trabalho de Cordeiro, Azevedo e Mattos (2004).

${ }^{9}$ As observações aqui realizadas estão baseadas na análise do corpus que foi constituído por um total de 36 textos, além disso, foram utilizadas as anotações do diário de classe da pesquisadora que acompanhou a aplicação da sequência didática.

\section{A TEXTUAL PRODUCTION FROM TEACHING PROCEDURES: A DESIGN AS WRITTEN APPEARANCE GUIDING TEACHING JOB}

\begin{abstract}
This work aims to reflect on the application of didactic instruments for teaching Portuguese Language, mainly focused on writing. For this purpose, we used the Sociodiscursivo Interactionism perspective (ISD), based on the writings of Bronckart $(1999,2006)$. The assumptions of Vygotsky (1988) were also extremely important for our research. As for the methodological instrument analysis, we use a Didactic Sequence (DOLZ, NOVERRAZ e SCHNEUWLY, 2004), whose purpose is the internalization of various genres of text. From the results of the application, was
\end{abstract}


marked the relationship between the conception of the institutions of writing and the way as this object is developed.

Keywords: Conception of writing. Textual production. Didactic sequence.

\section{REFERENCIAS}

ADAM, J. M. Les textes: types et prototypes. Paris: Nathan, 1992.

BAKHTIN, Mikhail. Estética da criação verbal. São Paulo: Martins Fontes, 1992.

BRONCKART. Jean-Paul. Atividade de linguagem, textos e discurso: por um interacionismo sócio-discursivo. São Paulo: Educ, 1999.

. Atividade de linguagem, discurso e desenvolvimento humano. Campinas:

Mercado de Letras, 2006.

CORDEIRO, G. S.; AZEVEDO, I. C. M.; MATTOS, V. L. Trabalhando com seqüências didáticas: uma proposta de ensino e de análise de narrativas de aventuras de viagens. Calidoscópio, São Leopoldo, v. 2, n. 1, p. 29-42, jan./jun. 2004.

DOLZ, J.; NOVERRAZ, M.; SCHNEUWLY, B. Seqüências didáticas para o oral e para a escrita: apresentação de um procedimento. Trad. Roxane Rojo e Glaís Cordeiro. In: SCHHNEUWLY, B.; DOLZ, J. Gêneros orais e escritos na escola. Campinas: Mercado das Letras, 2004. p. 95-128.

GUIMARÃES, A. M. M. Desenvolvimento de narrativas e o processo de construção social da escrita. Calidoscópio, São Leopoldo, v. 2, n. 2, p. 67-72, jul./dez. 2004.

MACHADO, Ana Raquel. O diário de leituras: a introdução de um novo instrumento na escola. São Paulo: Martins Fontes, 1998.

SCHHNEUWLY, B.; DOLZ, J. Gêneros orais e escritos na escola. Campinas: Mercado das Letras, 2004.

SCHHNEUWLY, Bernard. Gêneros e tipos de discurso: considerações psicológicas e ontogenéticas. Trad. Roxane Rojo e Glaís Cordeiro. In: SCHHNEUWLY, B.; DOLZ, J. Gêneros orais e escritos na escola. Campinas: Mercado das Letras, 2004. p. 2139.

VYGOTSKY, Liev S. A formação social da mente. 2. ed. São Paulo: Martins Fontes,1988. 